PII: S0735-1933(01)00253-6

\title{
A DIMENSIONLESS ANALYSIS OF RADIAL HEAT CONDUCTION WITH VARIABLE EXTERNAL CONVECTION BOUNDARY CONDITIONS
}

\author{
J. F. Branco \\ Departamento de Engenharia Mecânica e Gestão Industrial \\ Instituto Politécnico de Viseu \\ Campus Politécnico, 3504-510 VISEU, Portugal \\ C. T. Pinho \\ CEFT-DEMEGI \\ Universidade do Porto \\ Rua Dr. Roberto Frias, 4200-465 PORTO, Portugal
}

R. A. Figueiredo

Departamento de Engenharia Mecânica

Universidade de Coimbra

Pinhal de Marrocos, 3030 COIMBRA, Portugal

(Communicated by J.W. Rose and A. Briggs)

\begin{abstract}
Radial heat conduction in insulated pipes under external convection is usually dealt with great detail in several heat transfer publications. However, an analysis carried out through the graphical representation of the dimensionless characteristic parameters, will allow a better understanding of the phenomenon. Here the dependence of the convection coefficient on the external radius and external surface temperature, typical of forced and free convection, is taken into account. Assuming a power law variation of the convection coefficient [1] and using the results of Sparrow [2], all the important dimensionless parameters, including the critical radius, are explicitly represented and compared with those arising in the case of the insulated sphere [3]. (1) 2001 Elsevier Science Ltd
\end{abstract}

\section{Introduction}

The well-known problem of radial heat conduction in insulated pipes is revisited in this work. The use of a dimensionless approach, similar to that employed by Branco et al. [3] in the study of heat conduction in the hollow sphere, allows a comprehensible graphical representation of the heat transfer process. The analysis is not restricted to constant convection coefficient, which is extensively treated in several heat transfer books (e.g. Incropera and DeWitt [4]). The cases of forced and natural convection, 
assuming a power law variation of the external convection coefficient, are also considered and the presented equations are simpler than the previously available in the literature.

Sparrow [2] and Simmons [5] used this kind of variation of the convection coefficient

$$
h_{o} \propto r_{o}{ }^{-p}\left|T_{o}-T_{\infty}\right|^{n}
$$

with $p \geq 0$ and $n \geq 0$, in the study of the critical insulation radius; however their results depend on the unknown insulation surface temperature $-T_{0}-$ as in the case of Sparrow's [2] equation

$$
r_{o, c r i t}=\frac{1-p}{1+n} \frac{k}{h_{o, c r u t}}
$$

Balmer [6] used the correlation developed by Churchill and Chu [7] for free convection around a horizontal cylinder to develop another equation for the critical insulation radius; in spite of being a more general equation, it is, as well, an implicit one. Russo and St. Cyr [8] presented equations for the minimum amount of insulation necessary to minimize the heat loss; however the only considered cases were of $h_{o}=$ const. and $h_{o} \propto r_{o}^{-p}$. Another equation for the critical radius, under conditions defined by Eq. (1), was also developed by the authors [9]; the approach used then is now extended to the other parameters arising in radial heat conduction.

\section{Forced and Natural Convection Over Cylindrical Bodies}

Experimental data show that, in many cases, the external convection coefficient on cylindrical pipes can be calculated through a power law equation. For example McAdams [1] correlates data for forced convection around a cylinder in cross-flow using a power law; a similar and widely used correlation $[10]$ is

$$
N u_{D}=B\left(R e_{D}\right)^{m} \operatorname{Pr}^{1 / 3}
$$

For natural convection around a horizontal cylinder McAdams [1] presents simplified dimensional equations for air and water. Morgan [11] suggests an equation of the type

$$
N u_{D}=C\left(R a_{D}\right)^{n}
$$

Values for $B, m, C$ and $n$ can be found in the literature (e.g. $[4,10])$ as a function of the Reynolds $\left(R e_{D}\right)$ or Rayleigh $\left(R a_{D}\right)$ number, respectively.

\section{Heat Conduction Under Free External Convection}

A semi-infinite tube of external radius $r_{i}$, protected with an insulation layer of thickness $e=r_{o}-r_{b}$ and thermal conductivity $k$, loses heat in natural convection regime. In the following analysis, the same set of dimensionless parameters used in [3] are employed 


$$
B i=\frac{h_{i} r_{1}}{k}, \quad r^{*}=\frac{r}{r_{1}}, \quad r_{o}^{*}=\frac{r_{o}}{r_{i}}, \quad T^{*}=\frac{T-T_{\infty}}{T_{i}-T_{\infty}}, \quad q^{*}=\frac{q}{q_{1}} \quad \text { and } \quad h^{*}=\frac{h}{h_{i}}
$$

where $B i$ is the characteristic Biot number and $r^{*}, T^{*}, q^{*}$ and $h^{*}$ are the radial coordinate, temperature difference, heat-transfer rate and heat transfer coefficient, all in dimensionless form. The subscript $i$ designates the inner insulation surface, $o$ the outer one and $\infty$ the surrounding fluid, away from the pipe. In the definition of the Biot number, the convection coefficient in the absence of insulation, $h_{i}$, is used for convenience.

A dimensionless equation, similar to Eq. (1)

$$
h_{o}^{*}=\left(r_{o}^{*}\right)^{m-1}\left(T_{o}^{*}\right)^{n}
$$

may be used instead of Eqs. (3) and (4). The forced convection case may be represented taking $n=0$, whereas in free convection $m=3 n$. The same simplifying assumptions used in [3] are considered: constant $m, n$ and fluid properties, calculated at an average film temperature. This means that the changes in $R e_{D}$ or $R a_{D}$, as the insulation thickness increases, are inside de intervals defined by Welty et al. [10]; or that new exponents $m$ and $n$ can be defined, covering the range of the characteristic number $-R e_{D}$ or $R a_{D}$.

\section{Temperature Distribution, Heat Transfer Rate, Critical and Minimum Insulation Radius}

Assuming constant overall properties for the insulating material and in the absence of heat generation, the steady-state conduction equation in cylindrical coordinates takes the form

$$
\frac{d^{2} T^{*}}{d r^{* 2}}+\frac{1}{r^{*}} \frac{d T^{*}}{d r^{*}}=0
$$

the boundary conditions being the inner temperature and the external convection coefficient $\left(T_{i}, h_{o}\right)$

$$
T^{*}\left(r_{i}^{*}\right)=1 \text { and }\left.\frac{d T^{*}}{d r_{i}^{*}}\right|_{r^{*}=r_{o}^{*}}=-B i h_{o}^{*} T_{o}^{*}
$$

The resulting temperature distribution in the insulation layer

$$
T^{*}=1-B i T_{o}^{*} h_{o}^{*} r_{o}^{*} \ln \left(r^{*}\right)=1-\left(1-T_{o}^{*}\right) \frac{\ln \left(r^{*}\right)}{\ln \left(r_{o}^{*}\right)}
$$

depends on the external surface temperature; this can be easily found introducing Eq. (6) into Eq. (9) to obtain an implicit equation, which can be easily solved using a standard numerical method.

$$
T_{o}^{*}=1-B i\left(r_{o}^{*}\right)^{m}\left(T_{o}^{*}\right)^{n+1} \ln \left(r_{o}^{*}\right)
$$

The dimensionless heat-transfer rate

$$
q^{*}=\left(r_{o}^{*}\right)^{m}\left(T_{o}^{*}\right)^{1+n}
$$

may be casted with Eq. (10) to obtain 


$$
q^{*}=\left(r_{a}^{*}\right)^{m}\left(1-B i \ln \left(r_{a}^{*}\right) q^{*}\right)^{1+n}
$$

Equation (12), graphically represented in Fig.1, shows that the heat loss depends on the defined Biot number, which controls the trend of the different curves, and on the thickness of the insulation. Figure 1 also shows that with low $B i$ the heat loss may increase.

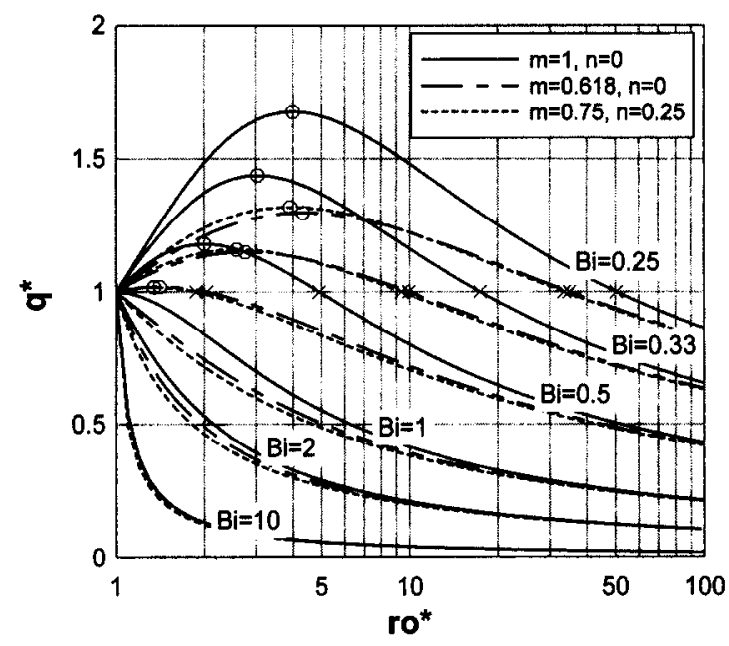

FIG. 1

Dimensionless heat transfer rate as a function of the insulation radius and the Biot number, for: $m=1, n=0 ; m=0.618, n=0 ; m=0.75, n=0.25$.

The critical radius [1] may be found differentiating Eq. (12) and setting the result to zero, to get

$$
\begin{aligned}
& q_{\max }^{*}=\frac{1}{B i\left((1+n) / m+\ln \left(r_{o, c r t}^{*}\right)\right)} \\
& \left(r_{o, c r u}^{*}\right)^{m}=\frac{m}{1+n} \frac{1}{B i}\left(1+\frac{m}{1+n} \ln \left(r_{o, \text { rri }}^{*}\right)\right)^{n}
\end{aligned}
$$

These equations show that, under a power law variation of the external convection coefficient, the limiting value of $B i$ for which a critical radius exists is

$$
B i<\frac{m}{1+n}
$$

When this occurs (small tube radius, large thermal conductivity of the insulation and small convection coefficient) the heat loss can only be reduced when $r_{o}>r_{0, m n}$, Chapman [12]. The minimum insulation radius, $r_{o, m n}$, is indicated with " $\times$ " marks in Fig. 1 and can be obtained solving the equation

$$
\left(r_{o, \min }^{*}\right)^{m}\left(1-B i \ln \left(r_{o, \min }^{*}\right)\right)^{1+n}=1
$$




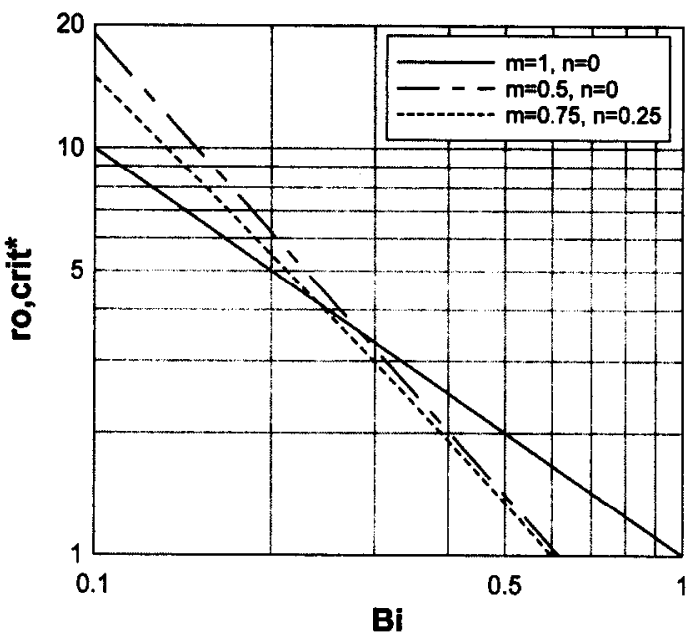

FIG. 2

Critical insulation radius as a function of the Biot number, for: $m=1, n=0 ; m=0.618, n=0$; $m=0.75, n=0.25$.

The critical and the minimum insulation radius are represented in Figs. 2 and 3, which, with Fig. 1, show that $r_{o, m i n}$ can be much greater than $r_{\text {o.crit }}$. Practical applications can be found in electricity and electronics [8].

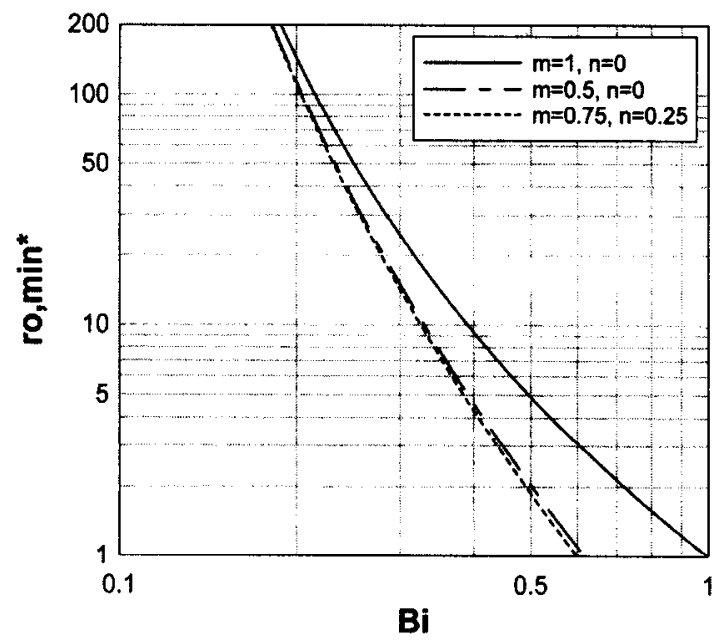

FIG. 3

Minimum insulation radius as a function of the Biot number, for $m=1, n=0 ; m=0.618, n=0$; $m=0.75, n=0.25$. 


\section{Comparison With Forced Convection and Constant Convection Coefficient}

Equations for forced convection and for constant heat transfer coefficient may be immediately found setting $n=0$, or $m=1$ and $n=0$, respectively, in Eqs. (9)-(16). Table 1 summarizes the obtained results.

TABLE 1

Heat Conduction in an Insulated Pipe: Forced Convection and Constant Heat Transfer Coefficient

Forced convection $(n=0,0<m<1)$ $h_{o}=$ const. $(n=0, m=1)$
$T^{*} \quad 1-\frac{B i\left(r_{o}^{*}\right)^{m} \ln \left(r^{*}\right)}{1+B i\left(r_{o}^{*}\right)^{m} \ln \left(r_{o}^{*}\right)}$
$1-\frac{B i r_{o}^{*} \ln \left(r^{*}\right)}{1+B i r_{o}^{*} \ln \left(r_{o}^{*}\right)}$
$q^{*} \quad \frac{\left(r_{o}^{*}\right)^{m}}{1+B i\left(r_{o}^{*}\right)^{m} \ln \left(r_{o}^{*}\right)}$
$\frac{r_{o}^{*}}{1+B i r_{o}^{*} \ln \left(r_{o}^{*}\right)}$
$r_{o, c r u t}^{*}$
$\left(\frac{m}{B i}\right)^{1 / m}$
$\frac{1}{B i}$
$q_{\max }^{*}$
$\frac{m / B i}{1+\ln (m / B i)}$
$\frac{1 / B i}{1+\ln (1 / B i)}$

Figures 1-3 show the dimensionless heat flux,Eq. (12), critical radius, Eq. (14), and minimum insulation radius, Eq. (16), for $h_{n}=$ const. $(m=1, n=0)$, forced $(m=0.618, n=0)$ and natural convection $(m=0.75, n=0.25)$. The insulation surface temperature, Eq. (10), is represented in Fig. 4.

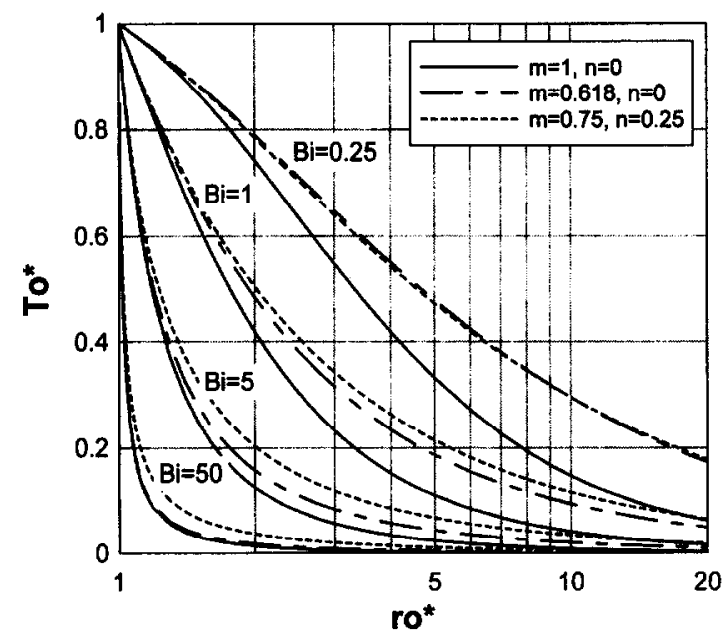

FIG. 4

Minimum insulation radius as a function of the Biot number, for $m=1, n=0$; $m=0.618, n=0 ; m=0.75, n=0.25$. 
TABLE 2

Radial Heat Conduction: Free Convection, Forced Convection and Constant Heat Transfer Coefficient

\begin{tabular}{|c|c|c|c|}
\hline Sphere & Free convection $(0<n<1, m=3 n)$ & Forced convection $(n=0,0<m<1)$ & $h_{0}=$ const. $(n=0, m=1)$ \\
\hline$T_{o}^{*}$ & $T_{o}^{*}=1-B i\left(r_{o}^{*}\right)^{1+m}\left(T_{o}^{*}\right)^{1+n}\left(1-\frac{1}{r_{o}^{*}}\right)$ & $\frac{1}{1+B i\left(r_{o}^{*}\right)^{m}\left(r_{o}^{*}-1\right)}$ & $\frac{1}{1+B i r_{o}^{*}\left(r_{o}^{*}-1\right)}$ \\
\hline$q^{*}$ & $q^{*}=\left(r_{o}^{*}\right)^{1+m}\left(1-B i\left(1-\frac{1}{r_{o}^{*}}\right) q^{*}\right)^{1+n}$ & $\frac{\left(r_{o}^{*}\right)^{1+m}}{1+B i\left(r_{o}^{*}\right)^{1+m}\left(1-1 / r_{o}^{*}\right)}$ & $\frac{\left(r_{0}^{*}\right)^{2}}{1+B i\left(r_{o}^{*}\right)^{2}\left(1-1 / r_{o}^{*}\right)}$ \\
\hline$r_{o, c r i t}^{*}$ & $\left(r_{o, c r i t}^{*}\right)^{m}=\frac{1+m}{1+n} \frac{1}{B i}\left(1+\frac{1+m}{1+n}\left(r_{o, c r t}^{*}-1\right)\right)^{n}$ & $\left(\frac{1+m}{B i}\right)^{1 / m}$ & $\frac{2}{B i}$ \\
\hline$r_{o, m i n}^{*}$ & $\left(r_{o, m i n}^{*}\right)^{m-n}\left(r_{o, m i n}^{*}-B i\left(r_{v, \text { min }}^{*}-1\right)\right)^{1+n}=1$ & $\left(r_{o, \min }^{*}\right)^{m}\left(r_{o, \min }^{*}-B i\left(r_{0, \min }^{\cdot}-1\right)\right)=1$ & $\frac{1}{B i-1}$ \\
\hline & $r_{o, \text { crit }}^{*}$ & $(1+m)^{(m+1) / m}$ & 4 \\
\hline$q_{\max }$ & $B i\left((1+n) /(1+m)+\left(r_{o, c r i t}^{*}-1\right)\right)$ & $B i\left((1+m)^{(m+1) / m}-m B i^{1 / m}\right)$ & $\overline{B i(4-B i)}$ \\
\hline Cylinder & Free convection $(0<n<1, m=3 n)$ & Forced convection $(n=0,0<m<1)$ & $h_{o}=$ const.$(n=0, m=1)$ \\
\hline$T_{o}^{*}$ & $T_{o}^{*}=1-B i\left(r_{o}^{*}\right)^{m}\left(T_{o}^{*}\right)^{n+1} \ln \left(r_{o}^{*}\right)$ & $\frac{1}{1+B i\left(r_{o}^{*}\right)^{m} \ln \left(r_{o}^{*}\right)}$ & $\frac{1}{1+B i r_{o}^{*} \ln \left(r_{o}^{*}\right)}$ \\
\hline$q^{*}$ & $q^{*}=\left(r_{o}^{*}\right)^{m}\left(1-B i \ln \left(r_{o}^{*}\right) q^{*}\right)^{1+n}$ & $\frac{\left(r_{o}^{*}\right)^{m}}{1+B i\left(r_{o}^{*}\right)^{m} \ln \left(r_{o}^{*}\right)}$ & $\frac{r_{o}^{*}}{1+B i r_{o}^{*} \ln \left(r_{o}^{*}\right)}$ \\
\hline$r_{o, c r i t}^{*}$ & $\left(r_{o, c r u t}^{*}\right)^{m}=\frac{m}{1+n} \frac{1}{B i}\left(1+\frac{m}{1+n} \ln \left(r_{o, c r i t}^{*}\right)\right)^{n}$ & $\left(\frac{m}{B i}\right)^{1 / m}$ & $\frac{1}{B i}$ \\
\hline$r_{o, \min }^{*}$ & $\left(r_{o, \text { min }}^{*}\right)^{m}\left(1-B i \ln \left(r_{o, \text { min }}^{*}\right)\right)^{1+n}=1$ & $\left(r_{o, \min }^{*}\right)^{m}\left(1-B i \ln \left(r_{o, \min }^{*}\right)\right)=1$ & $\left(r_{o, \min }^{*}\right)\left(1-B i \ln \left(r_{o, \min }^{*}\right)\right)=1$ \\
\hline \multirow{2}{*}{$q_{\max }^{*}$} & 1 & $m / B i$ & $1 / B i$ \\
\hline & $\overline{B i\left((1+n) / m+\ln \left(r_{o, c r t}^{*}\right)\right)}$ & $1+\ln (m / B i)$ & $1+\ln (1 / B i)$ \\
\hline
\end{tabular}




\section{Conclusion}

Using a more a realistic model of the convection coefficient, Eqs. (3) and (4), than the constant one, it can be seen that the heat-transfer rate diminishes, the insulation temperature increases and the minimum insulation radius decreases. These conclusions are in agreement with the expected trends, since the external convection coefficient, given by Eqs. (3) and (4), decreases as the insulation thickness increases. Comparing with the case of $h_{o}=$ const. the critical radius has a different behavior (Fig. 2). For $B i$ close to unity, it assumes a smaller value. But for lower values of $B i$ an inversion may be observed. This can be detected looking at Eq. (2): although the corrective factor is smaller than unity, the influence of $h_{o}$, which decreases with the insulation radius, reverses the situation. The error made when considering $h_{o}=$ const. diminishes with increasing Biot numbers. Thus this kind of simplification can be made in some practical situations, but in the evaluation of the critical or minimum insulation radius, it is not reasonable.

Table 2 summarizes the obtained results for the cylinder and for the sphere [3].

\section{Acknowledgements}

PRODEP II (Programa de Desenvolvimento Educativo para Portugal) supported the work of the first author. Grant number 517/2000 from FLAD (Fundação Luso-Americana) is also gratefully acknowledged.

\section{Nomenclature}

$B, C \quad$ proportionality constants in equations (3) and (4), dimensionless

$\mathrm{Bi} \quad$ Biot number, $h_{i} r_{\mathrm{t}} / k$, dimensionless

$D \quad$ external diameter, $\mathrm{m}$

$e \quad$ thickness of the insulation layer, $m$

$h, h^{*} \quad$ convection coefficient $\left(\mathrm{W} / \mathrm{m}^{2} \mathrm{~K}\right)$ and dimensionless convection coefficient

$k$ thermal conductivity of the insulation, $\mathrm{W} / \mathrm{mK}$

$m, n, p \quad$ exponents in equations (1), (3) and (4), dimensionless

$N u_{D} \quad$ Nusselt number based on diameter, dimensionless

Pr Prandtl number, dimensionless

$q, q^{*} \quad$ heat transfer rate across the insulation (W) and dimensionless heat transfer rate $\left(q / q_{1}\right)$

$r, r^{*} \quad$ radial coordinate $(\mathrm{m})$ and dimensionless radial coordinate $\left(r / r_{1}\right)$

$R a_{D} \quad$ Raylcigh number based on diameter, dimensionless

$R e_{D} \quad$ Reynolds number based on diameter, dimensionless

$T, T^{*} \quad$ temperature $(\mathrm{K})$ and dimensionless temperature difference 


\section{Subscripts and Superscripts}

$\begin{array}{ll}\text { crit } & \text { critical radius } \\ i & \text { inner insulation surface } \\ \max & \text { maximum heat loss } \\ \min & \text { minimum insulation radius } \\ o & \text { outer insulation surface } \\ * & \text { dimensionless variable } \\ \infty & \text { surrounding fluid }\end{array}$

\section{References}

1 W. H. McAdams, Heat Transmission, 3rd ed., p. 177, 258, 414, McGraw-Hill, New York (1954).

2 E. M. Sparrow, AIChE Journal 16 (1), 149 (1970).

3 J. F. Branco, C. T. Pinho and R. A. Figueiredo, Int. Comm. Heat Mass Transfer 27 (8), 1067 (2000).

4 F. P. Incropera and D. P. DeWitt, Fundamentals of Heat and Mass Transfer, 4th ed, p. 90, 369, 501, Wiley, New York (1996).

5 L. D. Simmons, J. Heat Transfer 98, 150 (1976).

6 R. T. Balmer, AIChE Journal 24, (3), 547 (1978).

7 S. W. Churchill and H. H. Chu, Int. J. Heat Mass Transfer 18, 1049 (1975).

8 E. P. Russo and W. W. St. Cyr, Electronic component cooling using critical radius concepts, INTERPack '97: Proc. of the 1997 PACIFIC/RIM ASME International Intersociety Electronic and Photonic Packaging Conference, Hawaii, Vol. 2, p. 1919-1923. ASME, New York (1997).

9 J. F. Branco, C. T. Pinho and R. A. Figueiredo, Critical radius for insulated pipes with variable external convection coefficient, NHTC2000: Proc. 2000 National Heat Transfer Conference, Pittsburgh, PA, paper NTHC2000-12009; ASME, New York (2000).

10 J. R. Welty, C. E. Wicks and R. E. Wilson, Fundamentals of Momentum, Heat and Mass Transfer 3rd ed., p. 358, 371, Wiley, New York (1984).

11 V. T. Morgan, The overall Convective Heat Transfer from Smooth Circular Cylinders, in T. F. Irvine and J. P. Hartnett (eds.), Advances in Heat Transfer, pp. 199-264, Academic Press, New York (1975)

12 A. J. Chapman, Heat Transfer, 2nd ed., p. 62, Macmillan, New York (1967).

Received March 8, 2001 